\title{
126 \\ Patients with colorectal cancer expressed a loss of adulthood related to a loss of professional and sexual identity, dignity, privacy, independence, and ability to socialise
}

Rozmovits L, Ziebland S. Expressions of loss of adulthood in the narratives of people with colorectal cancer. Qual Health Res 2004; 14:187-203.

\section{Q In patients with colorectal cancer, what is the effect of the illness and treatment on sense of adulthood in relation to self identity?}

\section{DESIGN}

Qualitative study using illness narrative interviews.

\section{SETTING}

UK.

\section{PATIENTS}

39 patients (33-87 y, 51\% men) who were $28-68$ years of age at the time of diagnosis of colorectal cancer (any of Dukes stages of illness) were recruited using maximum variation sampling.

\section{METHODS}

Indepth narrative interviews were done in patients' homes for all but 3 patients, who were interviewed in a support group office. Patients were invited to tell their stories from the point at which they first suspected a problem and were then asked semistructured questions on several illness related issues. Interviews were audiotaped, transcribed, and analysed using the constant comparative method.

\section{MAIN FINDINGS}

An overarching theme of loss of adulthood emerged. 4 subthemes were related to the effect of the illness on self identity.

Loss of professional identity was experienced by some patients who had to abandon their careers or retire early because of the illness. Loss of professional identity meant more than a loss of work related tasks; it also included loss of ability to meet social expectations because of reduced control over bodily boundaries (eg, unpredictability of bowels affected job performance and fundamental aspects of socially expected adult identity).

Patients experienced a loss of ability to socialise as digestive dysfunction affected their ability to travel, socialise, eat away from home, and pursue leisure activities. Patients had to manage daily inconveniences that included loss of bowel control, chronic constipation, and forced changes in diet. For some patients, disruption of eating and bowel habits resulted in feelings of being housebound, isolated, and uncomfortable in social relationships. Loss of mobility and spontaneity (eg, with travelling) compromised adult identity.

Learning to manage a stoma: loss of dignity, privacy, and independence, was a subtheme described by 22 patients who had temporary or permanent stomas. Patients described feelings of anxiety about the experience of toilet training in adulthood, and worry over leaks, escaping smells, and intrusive noises. Loss of control over bowel function profoundly affected patients' sense of adult identity.

For correspondence: Dr $\mathrm{L}$ Rozmovits, Freelance Research Consultant, London, UK. rozmovits@blueyonder.co.uk

Sources of funding: Macmillan Cancer Relief; Citrina Trust; Department of Health.
Disruption of sexual identity was a subtheme that represented the impact of colorectal cancer and its treatment on sexual identity. Patients with stomas described the effects on sexual relationships, which ranged from no problem to some discomfort to withdrawal from sexual contact with partners.

\section{CONCLUSIONS}

Patients with colorectal cancer expressed a loss of adulthood. Loss of control over bowel function profoundly affected sense of adult identity. Patients described a loss of professional identity, dignity, privacy, independence, and sexual confidence and compromised ability to work, travel, and socialise.

\section{Commentary}

7 he study by Rozmovits and Ziebland reveals the potential impact of pelvic cancers on the physical, social, and interpersonal dimensions of human embodiment. The data are drawn from the stories of people with both temporary and permanent ileostomies and colostomies, and the narratives will resonate for professionals who have worked with patients with ostomies. The participants, of whom 22 had ostomies, emphasised that colorectal cancer challenges personal identity and disrupts the trust that we learn to place in our bodies. The inherent vulnerability introduced by a diagnosis of colorectal cancer is given powerful voice in this study. For example, life after bowel surgery can mean having to cope with the everyday risk of others noticing a leaking, smelly, or noisy stoma. In addition to adapting to such fundamental changes in body image, patients need to bear the existential threat associated with a cancer diagnosis. These findings support those of other recent studies of patients with gynaecological or prostate cancers.

It is now accepted that rehabilitation should be an integral phase of effective cancer care, and studies such as the one by Rozmovits and Ziebland provide evidence to help guide service development in this area. For practitioners, this study emphasises the need to speak openly with patients about the impact of colorectal cancer and its treatment on their sense of identity, including their sexual identity. Practitioners also have key roles in providing education and support related to living with a stoma. Finally, connecting patients with peer supports (eg, individuals, groups, or the DIPEx bowel cancer module, an internet resource based on illness narrative interviews ${ }^{2}$ ) may help them to recognise that they are not alone in their experiences and to identify new ways of living with colorectal cancer and maintaining a positive self identity.

Daniel Kelly, RN, PhD St Bartholomew School of Nursing City University London, UK

1 Maliski SL, Heilemann MV, McCorkle R. Mastery of postprostatectomy incontinence and impotence: his work, her work, our work. Oncol Nurs Forum 2001;28:985-92.

2 DIPEX.org website. Personal experiences of health and illness. hitp:// www.dipex.org 